Investigations

\title{
Quarantine Protective Measures against the Melon Flies (Myiopardalis Pardalina Big.) in Kazakhstan
}

\author{
${ }^{1}$ Bayan Boytayevna Toyzhigitova, ${ }^{2}$ Saparbek Yskak, ${ }^{2}$ Almat Salamatovich Dinasilov, ${ }^{3}$ Peter Kochinski, \\ ${ }^{4}$ Zeynolla Raikhanovich Ershin, ${ }^{5}$ Baktigyl Raimbekova and ${ }^{5}$ Ayagoz Zhunussova \\ ${ }^{1}$ Kazakh National Agrarian University, Kazakhstan, 050010, Almaty, Abai Avenue, 8, Kazakhstan \\ ${ }^{2}$ LLP "Kazakh Research Institute of Protection and Quarantine of Plants Named after Jazctna Jeenbaeva", \\ Kazakhstan, Almaty city, 050070, Nauryzbai district, a Neighborhood of Rahat, Kazbek bi Street 1, Kazakhstan \\ ${ }^{3}$ Instytut Ochrony Roslin-Panstwowy Instytut Badawczy, Jozefa Chelmonskiego 22, 15-195 Bialystok, Polska, Kazakhstan \\ "JSC"Park of Nuclear Technologies", The Respublic of Kazakhstan, \\ 071100, East Kazakhstan Region, Kurchatov city, 18/1, Kurchatov Street, Kazakhstan \\ ${ }^{5}$ Kazakh National Agrarian University, Kazakhstan, 050010, Almaty, Abai Avenue, 8, Kazakhstan
}

Article history

Received: 09-08-2017

Revised: 24-08-2017

Accepted: 29-09-2017

Corresponding Author:

Bayan Boytayevna

Toyzhigitova

Kazakh National Agrarian

University, Kazakhstan,

050010, Almaty, Abai Avenue,

8, Kazakhstan

Email: toyzhigitova@yandex.ru

\begin{abstract}
In 2015-2016 years for the purpose of studying the most acceptable methods of eradicating foci of melon flies, the effectiveness of chemical and agro technical measures in field conditions of the Kyzylorda region of the Republic of Kazakhstan were determined. Practical experience in the application of various phytosanitary measures for the localization and elimination of the melon flies foci was summarized. The principal role in limiting the further spread of the pest has been assigned to strict observance of quarantine phytosanitary measures. The effectiveness of agro technical and chemical measures applied against the melon flies has been assessed. The elements of the melon flies mass reproduction technology have been developed, including the collection of melon fly puparia in nature, their delivery to the laboratory, storage, emergence of flies from puparia, feeding, reproduction and obtaining laboratory population. The most optimal dose of radiation has been established for the treatment and release of sterile males.
\end{abstract}

Keywords: Melon Fly, Biology, Phases of Development, Agrotechnical, Chemical Measures, Dose of Radiation, Sterility

\section{Introduction}

The melon fly (Myiopardalis pardalina Big.) is a dangerous pest of melons, watermelon, pumpkin and cucumber all over the world (Toreniyazov 2010; Saparmamedova, 2004). In 2004, in Kazakhstan, the first foci of the melon flies were identified in the Kyzylorda region bordering with Karakalpakstan. Thus, according to the data of the Plant Quarantine Department of the Kyzylorda Regional Territorial Inspectorate of the Ministry of Agriculture of the Republic of Kazakhstan, 2010 hectares of melons were treated in 2011 and 6253,5 hectares -in 2017. In the Kazalinsk, Karmakshi, Zhalagash, Syrdarya, Shiali, Zhanakorgan districts and in Kyzylorda almost $50 \%$ of the areas sown with melons and grounds were infected. Starting from 2011, the yield losses from the melon flies in the Kyzylorda and South Kazakhstan regions have ranged from 10 to 25\% and in some places equaled to $100 \%$.
According to the Inspectorate of Plant Quarantine in the South-Kazakhstan region, starting from 2012 the situation with the spread of the melon flies has become tenser. The foci were found in almost all areas of melon cultivation in the Arys, Baidibek, Kazygurt, Maktaaral, Otyrar, Ordabasin, Saryagash, Shardara and Turkestan regions and a quarantine regime has been declared. Despite the ongoing quarantine and protective measures against the melon flies, the area subject to treatment has been increasing every year.

In the South-Kazakhstan region the infected area was 4,237 hectares. New pest foci had been identified in the Baidibek, Maktaaral, Otyrar, Saryagash, Turkestan and Shardara regions on an area of 1,610 hectares. Population of the quarantine facility with the new foci was due to non-compliance with agro technical control measures, measures for utilization and liquidation of infected fruits; the increased
Science

Publications

(C) 2017 Bayan Boytayevna Toyzhigitova, Saparbek Yskak, Almat Salamatovich Dinasilov Peter Kochinski, Zeynolla Raikhanovich Ershin, Baktigyl Raimbekova and Ayagoz Zhunussova. This open access article is distributed under a Creative Commons Attribution (CC-BY) 3.0 license. 
acreage of melons and abandoned contaminated melons after the first crop. The uncontrolled trade in melons and gourds on highways and railway stations had also played its negative role.

Weather-climatic conditions of the whole vegetation period have had a universally favorable influence for the pest development this year.

In the Kyzylorda region, 1,900 hectares have been infected. The infection rate remains at the level of last year. In the Zhambyl region, 55.5 hectares have been infected and new pest foci with an area of 10.1 hectares have been identified in Zhambyl (Akbastau rural county, Erbol farm-0.1 hectare), Shuisk (Dalakainar rural county, "DIas" farm-5 hectares) and Talas (Oyik rural county, "Koyshybai ata" farm -5 hectares). In the West-Kazakhstan region, the pest has been found on 3.5 hectares, including a new 3 hectare focus in the Gubaydulla farm. In the Mangistau region, the infected areas (53.5 hectares) have been found in the territories of the Karakia, Zhyngyldy, Tupkaragan and Mangistau districts.

A new center of infection has been identified in Atyrau region, on the territory of the Rakusha farm in the Yerkinkala rural county of the city of Atyrau with an area of 4 hectares.

In 2017, the planned volume of chemical control measures to fight against the melon fly is $6,253.5$ hectares. The areas to be subjected to chemical treatment have been planned based on the actual contaminated areas. In case of non-compliance with quarantine measures to localize and eliminate the foci of the quarantine facility, an increase in contaminated areas is possible. Moreover, favorable weather and climate conditions of habitats, as well as biological characteristics of the pest, can contribute to an increase in foci, since the migration can take place during the flight of flies, reaching 5-7 km (Yskak et al., 2016).

The methods used to protect melons from this pest, using agro technical and chemical methods of combating, do not solve the issue of eliminating the foci of this quarantine pest.

Multiple treatments of crops with insecticides led to the formation of pest resistance to chemical preparations. Despite the funds allocated by the state, the issue of combating the melon fly remains very relevant. The further strengthening of the pesticide press will not solve the problem with the melon fly and will inflict exorbitant damage to the environment and human health. In this regard, it is necessary to develop an ecologic system for protecting melons from a melon fly, the parameters of which include the release of insects sterilized by radiation.
The Joint FAO/IAEA Division has been using isotopes and radiation in insect pest control since 1964. Ionizing radiation is used for the Sexual Sterilization of insects (SST). The use of the SST is the basis of the program of the Insecticide and Pest Control Section of the Joint FAO/IAEA Division. The program for the application of SST in the field to eliminate the Mediterranean fruit fly is actively supported. The laboratory of mass insect rearing in Tapachula, Mexico, produces over 500 million fruit flies per week. The VIENNA 8 tsl line represents one of the successful results of the joint work of the IAEA (International Atomic Energy Agency) and the Food and Agriculture Organization (FAO), which makes it possible to produce more than four billion sterile insects, 3.5 billion of which are the Mediterranean flies (Sagitov et al., 2015).

At present, the treatment of fruit flies with a dose of $150 \mathrm{~Gy}$ is recommended to prevent the development of adult flies of the Tephritidae family, as well as the other pests (Bustos et al., 2004; Follett and Armstrong, 2004; Aleksakhin et al., 2014).

To test these methods and implement the current programs at the initial stage, the elements of the method for mass breeding of melon fly in the laboratory have been worked out.

In recent years, the pest has quickly spread to the Zhambyl, West-Kazakhstan, Atyrau, Mangystau regions causing huge losses to melon-growing of the republic (Fig. 1-4).

According to the data of the Ministry of Agriculture of the Republic of Kazakhstan, the area of foci of the flies on the territory of the Republic of Kazakhstan is estimated at 13,000 hectares, i.e., about $15 \%$ of its potential range of phytosanitary risk (Yskak et al., 2016).

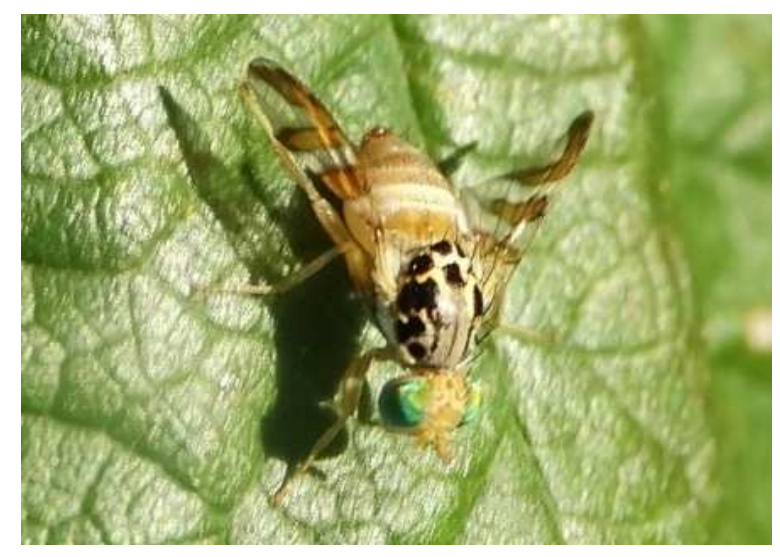

Fig. 1: Melon fly (Myiopardalis pardalina Big.) 


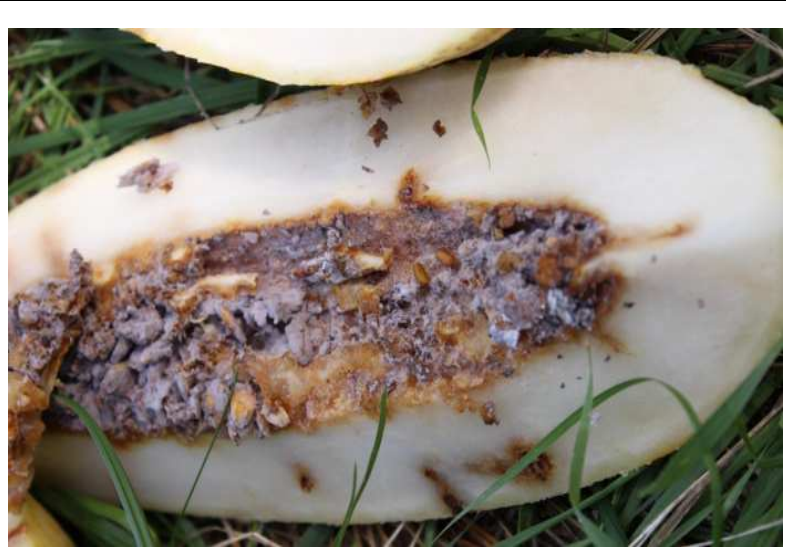

Fig. 2: Melon fruit damaged by melon fly

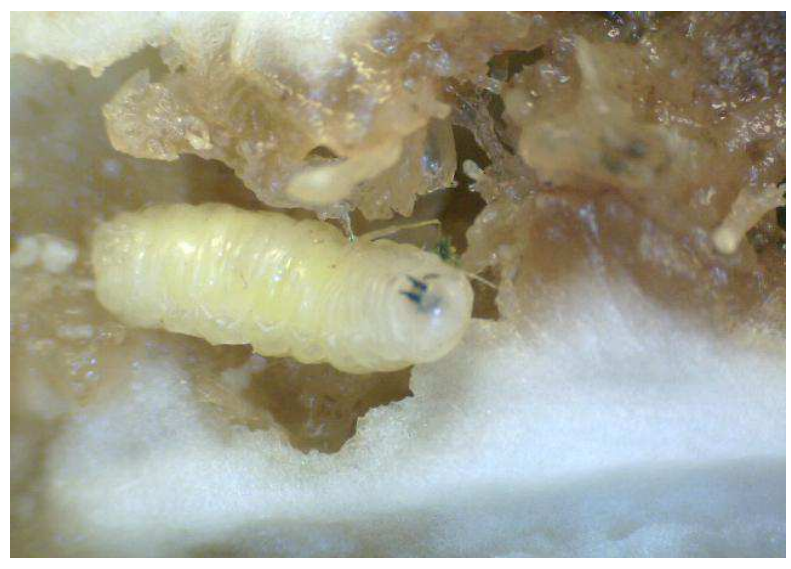

Fig. 3: Larvae of a melon fly inside a damaged fruit

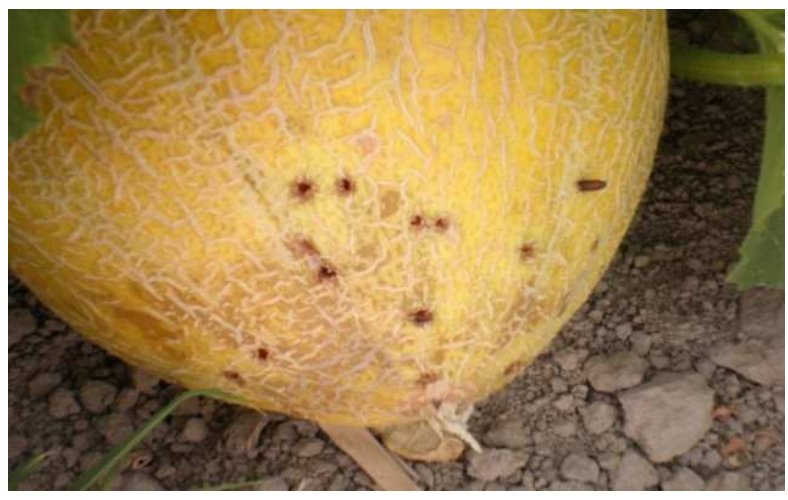

Fig. 4: The transformation of larvae into puparia sometimes occurs when larvae leave the damaged melon fruit

\section{Materials and Methods}

Field work was carried out in the Kyzylorda and South Kazakhstan regions and in the entomology laboratory of the Plant Quarantine Department of KazNIIZiKR LLP (Kazakh Research Institute for Plant Protection and Quarantine).
The identification of the relative abundance of the melon flies began at the inception of melon fruits and before harvesting (Fsulati, 1971). When counting, on each diagonal of the field 50 fruits were examined, the number of nubs, tubercles with eggs, larvae of flies and exit holes of larvae were taken into account. To study the wintering areas and the depth of location of the puparia of the melon flies, excavations were carried out in the field. In the fields under the melons, soil samples were taken based on 18 samples per 1 ha, layer by layer. The soil sampling depth was $0-5,5-10$, $10-15 \mathrm{~cm}$, the size of the site $-25 \times 25 \mathrm{~cm}$, located in staggered order. To establish the periods of the melon fly generations' development, it was nourished in cages located in fields and in insectaria, in conditions close to natural ones. When studying the effectiveness of catching flies using pheromone traps, the obtained results were compared to the sweep-net method results with 50 double strokes when passing along the diagonal of the field.

The biological effectiveness of the use of insecticides was determined by counting the melon damaged and undamaged by the larvae of the melon flies on the areas treated. The biological efficiency of the preparation had been calculated using the Abbot formula (Yskak et al., 2016).

Where:

$$
E=\frac{a-b}{a} * 100
$$

$E=$ Theefficiency expressed as thepercentage of reduction in plant damage, adjusted for control

$a=$ Thenumber of damaged plants in trial versions at a given recording time; and

$b=$ The number of unaffected plants in control at a given recording time

Chemical treatments were carried out using preparations according to the (Toyzhigitova et al., 2017.)

In order to determine the competitiveness of sterile males and establish the periods of the melon fly generations development, it was nourished in cages located in fields and in insectaria, in conditions close to natural ones.

The data obtained served as the basis for the development of a schematic diagram of the bioconveyor for mass rearing, taking into account the determination of the optimum keeping regimes (temperature, humidity, photoperiod), fodder plant and/or artificial feed, the laboratory master female population, storage. The development of the technology elements for mass rearing of radiation- 
sterilized male melon flies was carried out in accordance with international phytosanitary standards (Sagitov et al., 2015).

\section{Results}

The system of protection of melons and gourds from melon fly mainly relies on agrotechnical and chemical measures. To prevent the emergence of new foci of melon flies, the following quarantine phytosanitary measures are required: Import of melon crops from zones and places of production free from melon flies; inspection of products before export and at entry points; the products must be imported with a phytosanitary certificate; ban on the export of melon crops from contaminated areas, where the quarantine regime has been declared. There is a set of protective measures to fight against the melon flies, which is based on the characteristics of pest biology:

- The crop rotation must be observed: To return melon to its original location no earlier than after 4 years. The distance between crops of late and early ripening varieties should be at least $3-5 \mathrm{~km}$

- Planting the melons under the film is recommended. Melon seeds give early shoots and in 50-60 days the fruits of early varieties have time to enter the maturation phase, when the melon fruits become weakly damaged by a melon fly

- Considering that the pest lays eggs on fruits that appeared at the end of the growing season, the remaining unripe crop should be fully harvested before the larvae exit and buried at a depth of $70-100 \mathrm{~cm}$
- The fall-plowing after harvesting to a depth of at least $30 \mathrm{~cm}$ and flooding the fields are the recommended methods. As a result, some of the pupae are eaten by birds. In the spring the flies do not fly out of the pupae, found in deeper layers of soil

- Chemical measures arethemost effective in the following terms: The first one - in the flowering phase, when the melon fly appears in the fields, the second one - when the first generation of pests appears massively, coinciding with the period of formation of fruits $3-5 \mathrm{~cm}$ in size, the third one -during the mass development of the second generation (Fig. 5)

Field experiments were established to determine the biological effectiveness of insecticides against the melon flies experimental design 1.

At the end of melon flowering, treatment with Enjio 247 SC (Thiamethoxam, 141 gl + lambda-cyhalothrin, $106 \mathrm{~g} \mathrm{~L}^{-1}$ ) Syngenta Crop Protection AG, Switzerland is performed $-0.25 \mathrm{~L} \mathrm{ha}^{-1}, 5$ ha -1.251 .

In the period of fruit formation,treatment with NURELL D, C.E. (Chlorpyrifos, $500 \mathrm{~g} \mathrm{~L} \mathrm{~L}^{-1}+$ cypermethrin, $50 \mathrm{~g} \mathrm{~L} \mathrm{~L}^{-1}$ ) Dow AgroScience, USAis performed- $0.7 \mathrm{lha}^{-1}-5$ ha -3.51 .

With the massive emergence of the second generation of the melon flies, treatment with Enjio 247 SC (Thiamethoxam, $141 \mathrm{~g} \mathrm{~L}^{-1}+$ lambda-cyhalothrin, $106 \mathrm{~g}$ $\left.\mathrm{L}^{-1}\right)$ Syngenta Crop Protection AG, Switzerlandis done$0.25 \mathrm{~L} \mathrm{ha}^{-1}, 5$ ha -1.251 .

The treatments were carried out by a backpack motor sprayer, the flow rate of the working fluid was based on $200 \mathrm{~L} \mathrm{ha}^{-1}$. The treatments under the second scheme were carried out at the same time, using the Nurell D preparation(chlorpyrifos, 500 $\mathrm{g} \mathrm{L} \mathrm{L}^{-1}+$ cypermethrin, $50 \mathrm{~g} \mathrm{~L}^{-1}$ ) - $0.7 \mathrm{~L} \mathrm{ha}^{-1}$.

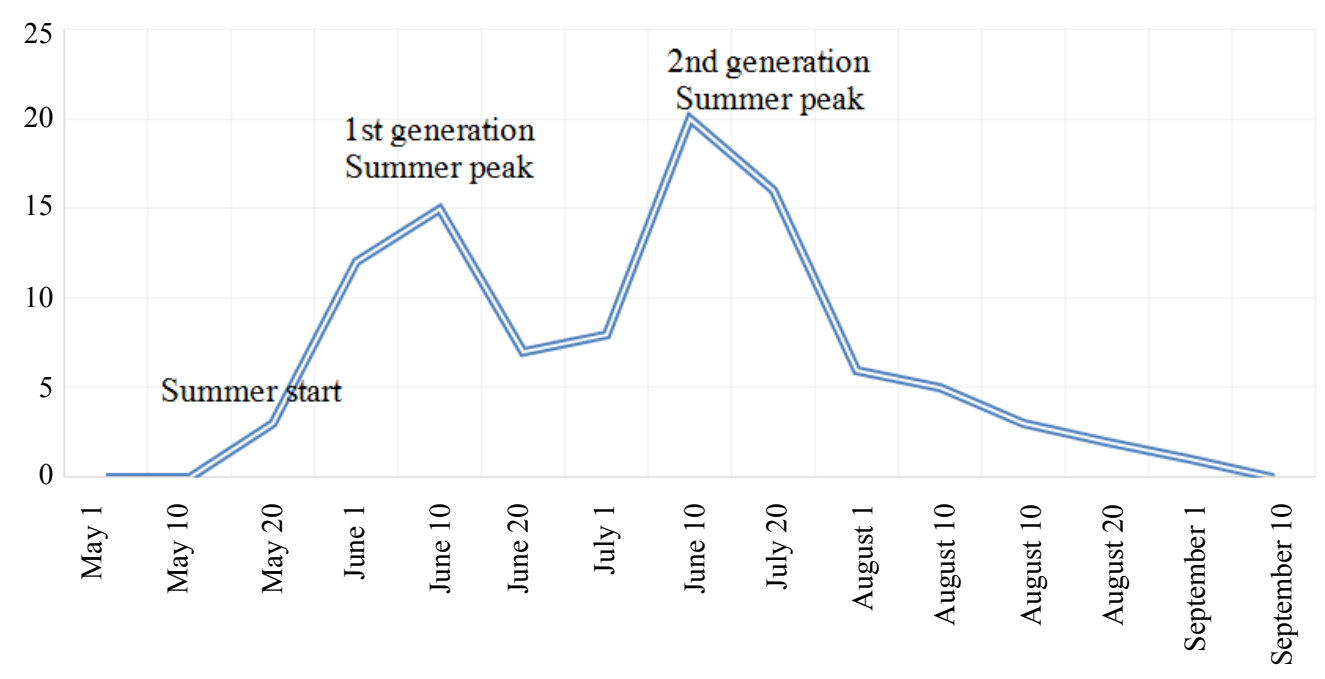

Fig. 5: Number of melon flies during the vegetation period (the Kyzylorda region, 2015-2016) 


\section{Discussion}

Treatment with Enjio $247 \mathrm{SC}-0.25 \mathrm{~L} \mathrm{ha}^{-1}$-performed at the end of melon flowering; treatment with NURELL D, C.E. $-0.7 \mathrm{~L} \mathrm{ha}^{-1}$-performed in the period of fruit formation; treatment with Enjio $247 \mathrm{SC}-0.25 \mathrm{~L} \mathrm{ha}^{-1}$ performed with the massive emergence of the second generation of the melon flies showed that the melon fruit infection with the larvae decreased by $89.0-91.3 \%$. Application of the NURELL D, C.E. reference preparation $0.7 \mathrm{~L} \mathrm{ha}^{-1}$ in the same period reduces the damage by 83.9$90.4 \%$. In addition, the increase in the yield of healthy fruits was $80.2-77.5 \mathrm{c} / \mathrm{ha}$ (Table 1 and 2).

The technology of mass reproduction of the flies has been developed. The technological scheme consists of the following elements: The collection of melon fly puparia in nature, delivery to the laboratory, storage, removal of flies from puparia, feeding, reproduction and obtaining a laboratory population.

Collection of the melon fly puparia was carried out in places of its mass reproduction in the Kyzylorda and South Kazakhstan regions. In July-August, after completing meals the larvae of the melon flies leave the fruit. Then they pupate in the soil at a depth of 2-7 cm. To collect the puparia, places with a large number of damaged melons or their storage sites were selected. The soil was sieved on sieves with a hole diameter of $2 \mathrm{~mm}$. The collected material was labeled and sent to the laboratory for storage. At the time of collection the puparia were temporarily stored in a refrigerator at a temperature of +5 to $+10^{\circ} \mathrm{C}$. They were delivered to the laboratory in a thermocase within 1 day.
Storage of puparia to be used in laboratory experiments requires the development of storage regimes for short-term (up to 30 days) and long-term (1 to 12 months) storage. It has been established that for short-term storage it is sufficient to observe a temperature regime of +5 to $+10^{\circ} \mathrm{C}$. For long-term storage, the puparia aged at +5 to $+100^{\circ} \mathrm{C}$ for at least 10 days are transferred to a refrigerator with a temperature of 0 to $-50^{\circ} \mathrm{C}$.

When it has been necessary to grow imago, a phased increase in temperature to the optimum one $\left(20-25^{\circ} \mathrm{C}\right)$ for 3 days was used for laboratory experiments. The percentage of imago yield under these conditions ranged from 54 to $81 \%$ (Table 3).

The greatest yield of adult flies (78-81\%) was observed with long-term storage of puparia at a temperature of $-2^{\circ} \ldots-3^{\circ} \mathrm{C}$

Feeding of the population in the cages was carried out with cotton balls soaked with $10 \%$ sugar syrup, melon, watermelon and molasses (Table 4). The largest number of surviving flies was observed when they were fed with $10 \%$ solution of melon juice - 31 live flies. After mating, the flies infested the melon plants grown in the laboratory to obtain the wintering stage of the puparia.

The prepared melon fly puparia had been subjected to radiation sterilization at the ILU-10 electron accelerator of the Park Yadernykh Tekhnologiy JSC in the dose range from 25 to $150 \mathrm{~Gy}$ and after that the reproduction capacity of females was determined when mating with males treated with radiation (Table 5).

$\underline{\text { Table 1: Biological efficiency of insecticides against melon flies (the Kyzylorda region, 2015-2016) }}$

\begin{tabular}{|c|c|c|c|c|c|}
\hline \multirow[b]{2}{*}{ Item No. } & \multirow[b]{2}{*}{ Experimental design } & \multirow[b]{2}{*}{ Application rate } & \multirow[b]{2}{*}{ Repeatability } & \multicolumn{2}{|c|}{ Number of damage fruits } \\
\hline & & & & 1st generation & Before harvesting \\
\hline \multirow[t]{6}{*}{1} & Enjio $247 \mathrm{SC}$ & $0.25 \mathrm{~L} \mathrm{ha}^{-1}$ & 1 & 3.0 & 6.0 \\
\hline & Nurell D, C.E. & $0.7 \mathrm{~L} \mathrm{ha}^{-1}$ & 2 & 1.0 & 5.0 \\
\hline & Enjio $247 \mathrm{SC}$ & $0.25 \mathrm{~L} \mathrm{ha}^{-1}$ & 3 & 4.0 & 7.0 \\
\hline & & & 4 & 5.0 & 3.0 \\
\hline & & & Average & 3.3 & 5.3 \\
\hline & & & Biological efficiency & 89.0 & 91.3 \\
\hline \multirow[t]{6}{*}{2} & Nurell D, C.E. & $0.7 \mathrm{~L} \mathrm{ha}^{-1}$ & 1 & 3.0 & 7.0 \\
\hline & Nurell D, C.E. & $0.7 \mathrm{~L} \mathrm{ha}^{-1}$ & 2 & 5.0 & 3.0 \\
\hline & Nurell D, C.E. & $0.7 \mathrm{~L} \mathrm{ha}^{-1}$ & 3 & 4.0 & 5.0 \\
\hline & (standard) & & 4 & 7.0 & 8.0 \\
\hline & & & Average & 4.8 & 5.8 \\
\hline & & & Biological efficiency & 83.9 & 90.4 \\
\hline \multirow[t]{5}{*}{3} & Control (untreated) & & 1 & 30.0 & 56.0 \\
\hline & & & 2 & 37.0 & 64.0 \\
\hline & & & 3 & 28.0 & 71.0 \\
\hline & & & 4 & 23.0 & 49.0 \\
\hline & & & Average & 29.5 & 60.0 \\
\hline
\end{tabular}


Table 2: Economical efficiency of insecticides against melon flies (the Kyzylorda region, 2015-2016)

\begin{tabular}{lllll}
\hline Item No. & Experimental design & Application rate & Average yield, centner/ha & Addition, centner/ha \\
\hline 1 & Enjio 247 SC & $0.25 \mathrm{~L} \mathrm{ha}^{-1}$ & & \\
& Nurell D, C.E. & $0.7 \mathrm{~L} \mathrm{ha}^{-1}$ & 132.0 & \\
& Enjio 247 SC & $0.25 \mathrm{~L} \mathrm{ha}^{-1}$ & & \\
2 & Nurell D, C.E. & $0.7 \mathrm{~L} \mathrm{ha}^{-1}$ & & 77.5 \\
& Nurell D, C.E. & $0.7 \mathrm{~L} \mathrm{ha}^{-1}$ & & \\
& Nurell D, C.E. & $0.7 \mathrm{~L} \mathrm{ha}^{-1}$ & & - \\
& (Reference) & & 51.8 & \\
& Control (untreated) & &
\end{tabular}

Table 3: Influence of temperature of long-term storage of melon fly puparia during 2 months on the departure of flies, 2015

\begin{tabular}{lll}
\hline & Average for 4 replicates & \\
\hline Option, ${ }^{\circ} \mathrm{C}$ & Number of puparia, pcs. & Number of departed flies, pcs. \\
\hline 0 & 100 & 66 \\
-2 & 100 & 78 \\
-3 & 100 & 81 \\
-5 & 100 & 54 \\
\hline
\end{tabular}

Table 4: Survival of the melon flies when fed with different media ( 2 weeks), 2015

\begin{tabular}{llc}
\hline & Average for 4 replicates & Number of surviving flies \\
\hline Option & Imago amount & 17 \\
$10 \%$ Sugar solution & 50 & 31 \\
$10 \%$ Welon juice solution & 50 & 8 \\
$10 \%$ Molasses solution & 50 & 14 \\
\hline
\end{tabular}

Table 5: Influence of different radiation doses on the development of the melon flies, 2015

\begin{tabular}{llll}
\hline Experiment option & Repeatability & Survival rate of males, $\%$ ) & $\begin{array}{l}\text { Reproduction capacity of females, } \\
\text { pcs/individual }\end{array}$ \\
\hline Dose of absorbed radiation, & 1 & 68.0 & 2.0 \\
25 Gy & 2 & 56.0 & 4.0 \\
& 3 & 56.0 & 3.0 \\
Average & 4 & 46.0 & 7.0 \\
Dose of absorbed radiation, & 1 & 56.5 & 4.0 \\
50 Gy & 2 & 55.0 & 1.0 \\
& 3 & 49.0 & 0.0 \\
Average & 4 & 57.0 & 0.0 \\
Dose of absorbed radiation, & & 49.0 & 0.0 \\
100 Gy & 1 & 52.5 & 0.3 \\
& 2 & 12.0 & 0.0 \\
Average & 3 & 3.0 & 0.0 \\
Dose of absorbed radiation, & 4 & 9.0 & 0.0 \\
150 Gy & & 15.0 & 1.0 \\
& 1 & 9.8 & 0.3 \\
Average & 2 & 13.0 & 0.0 \\
Control, without processing & 3 & 2.0 & 0.0 \\
& 4 & 1.0 & 0.0 \\
& 1 & 3.0 & 0.0 \\
Average & 2 & 4.8 & 0.0 \\
& 3 & 67.0 & 23.0 \\
& 4 & 51.0 & 10.0 \\
& & 76.0 & 11.0 \\
& & 54.0 & 18.0 \\
& & 9.5 & 15.5 \\
\hline
\end{tabular}




\section{Conclusion}

It is advisable to perform treatments against melon flies in the flowering phase, the period of sets' formation and the appearance of the second generation of the pest. The following protection scheme has been tested: Treatment with Enjio 247 SC-0.25 L ha ${ }^{-1}$ at the end of melon flowering; treatment with NURELL D, C.E. - $0.7 \mathrm{~L} \mathrm{ha}^{-1}$ in the period of fruit formation; treatment with Enjio 247 SC - $0.25 \mathrm{~L} \mathrm{ha}^{-1}$ with the massive emergence of the second generation of the melon flies. The results of its implementation have shown that the melon fruit infection with the larvae decreased by $89.0-91.3 \%$. The use of the NURELL D (C.E. reference preparation, $0.7 \mathrm{~L} \mathrm{ha}^{-1}$ ) in the same period reduced the damage by $83.9-90.4 \%$. At the same time, the increase in the yield of healthy fruits was $80.2-77.5 \mathrm{c} / \mathrm{ha}$.

Sets that appeared in late August - early September mostly do not have time to ripen completely. Given that the pest lays eggs on these fruits, the crop remaining in the fields must be fully harvested before the larvae exit and buried at a depth of 50-100 cm, from where the pest emerges sporadically. In such areas, there are almost no adults seen in the spring following departure and the departed individuals appear too late.

The fall-plowing after harvesting to a depth of at least $30 \mathrm{~cm}$ is recommended. As a result, some of the pupae appear on the surface of the soil and are eaten by birds. From pupae found in deeper layers of soil, in the spring flies may not fly out, which drastically reduces the number of the hibernated pest generation on the fields.

The optimal dose of radiation for the treatment and release of sterile males, which provides sufficient survival of males for release and high sterility of females after mating, is $50 \mathrm{~Gy}$ of absorbed dose.

\section{Acknowledgement}

We thank university financial departments for support our study.

\section{Author's Contributions}

All authors equally contributed in this work.

\section{Ethics}

This article is original and contains unpublished material. The corresponding author confirms that all of the other authors have read and approved the manuscript and no ethical issues involved.

\section{References}

Aleksakhin, R.M., N.I. Sanzharova, G.V. Koz'min, S.A. Geras'kin and A.N. Palov, 2014. Perspektivy ispol'zovaniya radiatsionnykh tekhnologiy $\mathrm{V}$ agropromyshlennom komplekse Rossiyskoy Federatsii [Perspectives of the use of radiation technologies in the agro-industrial complex of the Russian Federation]. Bull. Russian Acad. Natural Sci., 1: 1-8.

Bustos, M.E., W. Enkerlin, J. Reyes and J. Toledo, 2004. Irradiation of mangoes as a postharvest quarantine treatment for fruit flies (Diptera: Tephritidae). J. Economic. Entomol., 97: 286-292.

Follett, P.A. and J.W. Armstrong, 2004. Revised irradiation doses to control melon fly, Mediterranean fruit fly and Oriental fruit fly (Diptera: Tephritidae) and a generic dose for tephritid fruit flies. J. Economic. Entomol., 97: 1254-1262.

Fsulati, K.K., 1971. Polevoye Izucheniye Nazemnykh Bespozvonochnykh. [Field Study of Terrestrial Invertebrates.] Textbook for Universities. 2nd Edn., Vysshaya Shkola, Moscow, pp: 424.

Sagitov, A.O., V.E. Kambulin, E.A. Badaev and A.S. Dinasilov, 2015. Quarantine of plants. 1st Edn., Almaty, Tutorial, pp: 242.

Saparmamedova, N.K., 2004. K izucheniyu dynnoy mukhi, myiopardalis pardalina big. (Diptera, tephritidae) v Turkmenii [To study the melon fly, myiopardalis pardalina Big. in turkmenia]. Entomol. Rev., 83: 517-520.

Toreniyazov, E.S., 2010. Bioekologiya Razvitiya Dynnoy Mukhi i Rekomendatsii po Bor'be. [Bioecology of the Development of Melon Fly and Recommendations for Fighting. 1st Edn., Nukus Branch of Tashkent State Agrarian University, Ministry of Agriculture and Water Resources of the Republic of Uzbekistan, pp: 32.

Toyzhigitova, B., B. Łozowicka, P. Kaczyński, S. Yskak and A. Dinasilov et al., 2017. Occurrence and Strategy for the control Myiopardalis Pardalina Bigot in Kazakhstan. 1st Edn., 57 Sesja Naukova, Poznan, pp: 117.

Yskak, S., A. Dinasilov and B.B. Toizhigitova, 2016. Actual problems of biological and environmental education in secondary and higher education: Innovation and experience. Proceedings of the International Scientific and Practical Conference Central Asian Melon Fly Quarantine Pest, (MFQ' 16), Almaty, pp: 418-422. 